\title{
Responsabilidad subjetiva en la delincuencia socioeconómica $\left.\left.{ }^{*}\right)^{(* *}\right)$
}

\section{Subjective Responsibility in Socioeconomic Criminality}

\author{
Mirentxu Corcoy Bidasolo ${ }^{(* * *)}$ \\ Universidad de Barcelona
}

Resumen: El concepto y contenido del dolo es uno de los temas centrales de la discusión dogmática en el ámbito del derecho penal. En este artículo se trata de plantear las cuestiones específicas que surgen cuando se trata de la prueba del tipo subjetivo en el ámbito de la delincuencia socioeconómica. Con esta finalidad se analiza la determinación de la autoría a partir del criterio de la competencia y del dolo derivado de ella, incluyendo la cuestión de la llamada ignorancia deliberada. En el trabajo se relacionan los problemas teóricos con los prácticos, en particular con la prueba en el proceso penal. En este aspecto adquiere gran relevancia la actual consideración, por parte de la jurisprudencia, del dolo como un hecho que debe ser probado a través de datos objetivos.

Palabras clave: Derecho Penal - Dolo - Estados mentales - Conocimiento - Ignorancia deliberada - Indiferencia - Voluntad - Principio acusatorio - Derecho de defensa

\begin{abstract}
The concept of willful intent is one of the most important discussions in Criminal Law. In this article, the author analyses the specific problems that arise regarding the proof of the subjective type in the ambit of socioeconomic criminality. To this end, the determination of the authorship of the crime is analyzed based on the criteria of competence and the willful intent that derives from it, as well as the question of the so-called willful blindness. The article aims to link theoretical and practical problems together, particularly, the proof in criminal proceedings. It is regarding this aspect that the modern jurisprudential conception of willful intent as a fact that must be proven through objective data acquires great relevance in this investigation.
\end{abstract}

Keywords: Criminal Law - Willful intent - Mental states - Knowledge - Willful blindness - Disregard - Willingness - Criminal procedure - Right to defense

$\left.{ }^{*}\right) \quad$ Nota del editor: el artículo fue recibido el 15 de febrero de 2019 y su publicación fue aprobada el 5 de abril de 2019.

${ }^{* *}$ Este trabajo se ha realizado en el contexto del proyecto I+D: "Teoría del delito y proceso penal: ¿dos instrumentos conciliables" (DER2014-59247-R)

${ }^{(* *)}$ Catedrática de Derecho Penal Doctora por la Universidad de Barcelona, obteniendo el grado con la máxima calificación. Ha sido directora del Departamento de Derecho Penal de la Universidad de Barcelona. Ha sido jefa de estudios de Criminología de la misma casa de estudios. Actualmente es profesora invitada en diversas universidades como la Austral de Buenos Aires, la Católica de Valparaíso, la Santo Tomás de Bogotá, la Universidad Federico II de Nápoles, la Universidad de Palermo. Correo electrónico: mcorcoy@gmail.com. 


\section{Introducción}

En el Derecho penal la discusión acerca del concepto y los requisitos del dolo ha dado lugar a innumerables trabajos sin que se haya logrado un consenso. Por ello, la discusión sigue abierta y en algunas de las últimas construcciones ha tomado un papel preponderante la cuestión procesal, así como la problemática que suscita la responsabilidad subjetiva en los delitos socioeconómicos. En relación con las cuestiones procesales, no puede olvidarse que las sentencias no reflejan la "verdad ontológica"/"verdad material" sino la "verdad procesal"|"verdad formal". Es decir, el respeto del derecho de defensa y de las garantías que de éste se derivan, determina que quien acusa es quien debe aportar las pruebas que pueden tomarse en consideración en la configuración de los hechos probados. Aun cuando en el proceso penal rige la libre valoración de la prueba, las conclusiones a las que llega el juzgador deben ser motivadas racionalmente, siguiendo los criterios de interpretación aceptados en Derecho. No son admisibles las presunciones, máxime cuando estas sean contrarias al reo. En virtud del principio in dubio pro reo el juzgador está obligado a condenar exclusivamente respecto de los hechos de los que, una vez practicadas las pruebas, no subsistan dudas. El respeto de estos principios tiene consecuencias especialmente relevantes en relación con los aspectos subjetivos del delito, puesto que según se interprete su concepto, la prueba en el proceso devendrá imposible y será sustituida por las convicciones subjetivas del juzgador que no estarán basadas en los hechos jurídico-penalmente relevantes, sino en consideraciones que nada tienen que ver con el fundamento de la sanción penal.

Esta cuestión es especialmente relevante en la delincuencia socioeconómica, atendiendo a la naturaleza de los delitos y al perfil de los autores en este ámbito. Por una parte, en general, no puede afirmarse que "quieran lesionar el bien jurídico", ya que lo que se "quiere" es la obtención de unos beneficios ilícitos, tanto si se trata de un delito fiscal o de blanqueo, como si lo es de un delito de corrupción o contra el medio ambiente. Por otra parte, las características de la atribución de autoría en el contexto de los delitos cometidos en el interno de la empresa, afecta también al contenido del dolo, lo que explica que la ignorancia deliberada se haya desarrollado especialmente en este ámbito. Otra de las razones de acudir a la ignorancia deliberada en este contexto puede encontrarse en que en los delitos socioeconómicos, generalmente, no está prevista la comisión imprudente. Ello conlleva que, de no poder probarse el dolo, los hechos quedarán impunes.

Desde una perspectiva dogmática es factible elaborar un concepto de dolo que responda a la concepción de que, en cada caso, se defienda respecto de la teoría del delito. No obstante, entiendo que por mucho que esos planteamientos sean lógicos y razonables, atendiendo a la perspectiva adoptada, no son válidos si en el proceso son disfuncionales. Disfuncionales porque alguno de los requisitos no pueda probarse o/y porque conlleven en la práctica soluciones poco conformes con un derecho penal del hecho y con el principio de proporcionalidad. Partir de la concepción clásica del dolo que requiere que concurra un elemento cognoscitivo y otro volitivo, concebido, como querer el resultado, determina que en el dolo eventual, la intención respecto de la producción del resultado se sustituya por su aceptación o la indiferencia frente a este. En esta línea, la jurisprudencia tradicional, para fundamentar el dolo, utiliza argumentos que se relacionan con aspectos internos de la conciencia del sujeto que, no solo no pueden ser probados en un proceso, sino que, en la mayoría de ocasiones, el propio autor también desconoce. Un primer problema surge a partir de la naturaleza de los datos objetivos que se utilizan como indicios de que el sujeto aceptó, aprobó o le fue indiferente la producción del resultado. La segunda cuestión que debemos plantearnos es por qué, partiendo de un Derecho penal del hecho, el desvalor es distinto según sea la actitud interna del autor. $Y$ estas son las cuestiones nucleares a la que tenemos que enfrentarnos y que plantean sintéticamente dos cuestiones: ¿en qué agrava el injusto que el sujeto acepte, apruebe o le sea indiferente el resultado? y ¿cómo puede probarse esa presunta aceptación, aprobación o indiferencia?

Sobre la primera cuestión podemos avanzar que desde un Derecho penal que pretende castigar hechos que lesionen o pongan en peligro bienes jurídico-penales, la gravedad del injusto no puede concretarse a partir de la bondad o maldad del carácter del sujeto, que pertenece a su intimidad. Atribuyendo una función de motivación a la norma primaria, el mayor desvalor de los hechos dolosos se fundamenta en la mayor contradicción de la norma que supone el actuar con plena conciencia del riesgo que con la conducta se está suscitando respecto del bien jurídico penal protegido, no en el carácter del sujeto ni en el móvil que le ha llevado a actuar de esa forma. Respecto de la actitud interna, la gravedad del injusto solo aumenta cuando esos pensamientos "malvados" se traducen en una mayor 
peligrosidad del hecho, como sucede, por ejemplo, cuando el autor actúa con alevosía o con ensañamiento.

Así mismo, surge un problema estrechamente relacionado con lo anterior y que afecta a la comprensión que se tenga del Derecho penal, en concreto, al principio de culpabilidad en sentido amplio, es decir, a la exclusión de la responsabilidad objetiva. Aceptar este principio determina que no se pueda castigar por un resultado que no estuviera abarcado por el dolo o la imprudencia del sujeto. Este planteamiento implica que no puede fundamentarse el dolo, en ningún caso, en la gravedad del suceso o en la alarma social. Sin entrar en la cuestión sobre si el resultado es una condición de punibilidad o si forma parte del injusto, lo que hoy día es doctrina prácticamente unánime es que no puede castigarse por resultados no imputables objetivamente a una conducta dolosa o imprudente.

Respecto al aspecto procesal, la cuestión se centra en que, a partir de las concepciones clásicas sobre el dolo, no es posible probar lo que el sujeto pensaba en el momento de los hechos y, lo que es muy probable, el sujeto tampoco sabe lo que quería en ese momento, como no fuera, en cada caso, alcanzar objetivos que en nada se relacionan con el hecho, en cuanto jurídico-penalmente relevante. No pueden confundirse las motivaciones que el sujeto tiene para llevar a efecto una determinada conducta con el dolo. En un proceso que reúna las garantías exigibles en un Estado de Derecho no es posible probar las intenciones del sujeto, que no se traduzcan en datos objetivos que puedan servir de indicio para esa atribución. Ello ha contribuido lógicamente a que el dolo se haya normativizado, tanto en la doctrina como en la jurisprudencia, sin que se hayan erradicado totalmente las posturas que siguen defendiendo ese elemento subjetivo (Feijoo 2010, 177 y siguientes) (Robles 2003, 191) $)^{(1)}$.

Siendo discutible, desde una perspectiva dogmática, que exista una única concepción del dolo que sea válida, en términos absolutos, tampoco puede afirmarse qué elementos o requisitos son esenciales. Obviando en este contexto la clásica discusión entre las teorías cognitivas y volitivas, en sus diferentes variantes, lo cierto es que, con independencia de la discusión dogmática, ésta no puede deslindarse del problema más relevante en la práctica: la prueba del dolo en el proceso (Kindhäuser $1984,96)^{(2)}$. No restando importancia a los problemas dogmáticos y político-criminales que suscitan unas y otras posturas, no es menos relevante que las diferentes teorías del dolo no pueden ni deben olvidar que el dolo es una adscripción, una imputación, y como tal debe probarse en el proceso (Hruschka 2005, 145 y siguientes) $)^{(3)}$. Por consiguiente, deben tomarse en consideración las consecuencias que en el proceso plantea la exigencia de la concurrencia de determinados elementos, esencialmente, los de naturaleza volitiva. Tampoco puede obviarse, que la calificación como dolo eventual en nada cambia ya que implica una condena por delito doloso.

El concepto de dolo eventual no es un término legal sino una construcción dogmática que se utiliza en la distinción entre dolo e imprudencia y que, en principio carece de consecuencias, respecto de la calificación jurídico-penal de los hechos y, en definitiva, respecto de la atribución de un injusto típico ni de la imposición de una pena. Legalmente sólo existen delitos dolosos e imprudentes, por consiguiente, desde la perspectiva del principio de legalidad requerir que el sujeto "quiera" la producción del resultado carece de fundamento. La intención puede ser relevante respecto de algunos delitos concretos, en los que, por su naturaleza, requieran una actuación del autor que implique una finalidad.

Así, por ejemplo, en la estafa se requiere engaño que induzca a error, lo que está estrechamente vinculado a la intención del sujeto, o respecto de determinadas agravantes, como las de ensañamiento o

(1) La referida normativización del dolo no supone la adopción de una concepción funcionalista del Derecho penal, entendiendo que la función de protección de bienes jurídicos se lleva a efecto a través de la estabilización de la norma, en el sentido defendido, entre otros por Feijoo Sánchez en "Funcionalismo y teoría del bien jurídico"; así como Robles Planas en La participación en el delito: fundamentos y límites.

(2) Kindhäuser ya puso de manifiesto que no tiene ningún sentido exigir un elemento en el dolo que luego no puede ser apreciado, incluyendo en la crítica todas las diversas acepciones que se han ido proponiendo como sustitutivos del "querer".

(3) Hruschka plantea los problemas procesales de la prueba del dolo, a partir del \& 244.2 StPO, que introduce el concepto de "hecho relevante para la decisión", afirmando que tales hechos son el objeto de la práctica de la prueba y entiende que el dolo, o al menos sus requisitos, forman parte de esos "hechos". Este planteamiento le lleva de forma absolutamente coherente a resultados análogos a los aquí planteados, al afirmar que, aun cuando se requiera un elemento volitivo, como en Alemania requiere la doctrina procesalista, equiparando ambos elementos, volitivo y cognitivo, entre ambos "existe una relación de dependencia según la cual, siempre que un autor lleva a cabo una determinada conducta bajo unas determinadas circunstancias, conociendo el carácter de la acción y de las circunstancias, quiere realizar también tanto la conducta como las circunstancias en cuestión". 
alevosía, que presuponen una intención de causar un dolor innecesario o buscar la indefensión de la víctima. Por el contrario, en muchos delitos, en concreto, por ejemplo, todos aquellos vinculados a actuaciones en sectores de riesgo permitido, como la seguridad en el consumo, el medio ambiente o la seguridad en el trabajo. En ellos, así como en la mayoría de los relacionados con el llamado Derecho penal de empresa o en los relativos al buen funcionamiento de la Administración pública o de Justicia, la intención del sujeto, excepto en casos absolutamente excepcionales, no persigue la producción del resultado previsto en el tipo sino beneficiarse de una u otra forma. En estos supuestos lo usual es que el autor pretenda alcanzar otros objetivos, como puede ser, en los ámbitos de riesgo permitido, conseguir terminar una obra en el plazo acordado (homicidio/lesión imputable a la infracción de normas esenciales de prevención de riesgos laborales); ordenar el cierre de la depuradora para reducir gastos (delito contra el medio ambiente); reducir la cantidad de dinero a ingresar a Hacienda para aumentar beneficios (delito fiscal).

Desde una perspectiva estrictamente de Derecho penal material, si la antijuridicidad se fundamenta en la gravedad del hecho y no en la bondad o maldad del autor -Derecho penal del hecho y no Derecho penal de autor- lo que el sujeto quiera o no es algo que pertenece a su fuero interno y que no debe ser objeto de valoración. Por otra parte, una concepción del Derecho penal fundamentada en la naturaleza imperativa de las normas penales, ya sean de prohibición o de mandato, supone que éstas tienen la finalidad de motivar al ciudadano para no realizar conductas idóneas para lesionar bienes jurídico-penales ${ }^{(4)}$. El resultado que pueda derivarse de esas conductas está en el origen de la prohibición, en la norma de valoración que lleva al legislador a establecer la de prohibición o mandato. Por consiguiente, lo que se tiene que valorar en el injusto son los hechos no los resultados, ya que su producción en el caso concreto no depende de la voluntad del sujeto sino del azar. El desvalor del injusto parte del desvalor del hecho, el desvalor del resultado solo puede servir para limitar el desvalor del hecho, cuando no se produzca el resultado o éste no sea imputable, tentativa versus consumación, o impunidad en los delitos imprudentes. Impunidad que en la actualidad se ve "suplida" a través de la creación de tipos en los que se protegen diversos ámbitos de riesgo, entre los que están los delitos contra la seguridad en el trabajo o contra la salud de los consumidores, así como muchos delitos socioeconómicos como la actual administración desleal o la corrupción en los negocios. Para condenar por estos delitos hay que probar, exclusivamente, que se ha creado un riesgo relevante para la seguridad en el consumo, para la competencia leal, y que el sujeto conocía ese riesgo. Es decir, el dolo abarca exclusivamente el riesgo inherente a la conducta, no la producción de resultados lesivos.

Por lo demás, y en la práctica incluso más importante, hay que resaltar que en el proceso es imposible probar lo que el sujeto quería por lo que finalmente la prueba se va a llevar a efecto a través de presunciones que no son válidas (o no deberían serlo) en Derecho penal. $Y$ ello, entre otras razones, ya apuntadas arriba, porque nos conduce a un Derecho penal de autor. Entender que la concurrencia del elemento volitivo es un requisito esencial del dolo tiene consecuencias inaceptables en el ámbito del proceso ya que se presume el dolo en determinadas personas que por sus antecedentes, por su carácter... se parte de que "querían" o "aceptaban" cualquier resultado lesivo y, por el contrario, se niega el dolo respecto de aquéllas que por su profesión, médicos, jueces, notarios, abogados, se presume que "en ningún caso querían"(5). En el extremo opuesto, admitiendo la problemática que las posturas psicologicistas suscitan, también se plantean problemas procesales de diversa índole si se aceptan reglas estáticas de atribución del dolo que vinculen a los tribunales inferiores, máxime cuando no son revisables en casación, especialmente en la delincuencia socioeconómica ${ }^{(6)}$.

El concepto de dolo que aquí nos interesa es el de "dolo natural", y no entraremos a considerar el dolus malus, que abarca también el conocimiento de la antijuridicidad del hecho. El dolus malus, que tradicionalmente había sido el concepto causalista de dolo, comprende tanto el conocimiento y voluntad de los hechos externos, como de su significación antijurídica. El conocimiento

(4) Cónfer. Mir Puig, Derecho Penal. Parte General, 2015, 75 y siguientes; sobre la distinción entre normas de valoración y normas de determinación.

(5) Cónfer. Corcoy, El delito imprudente. Criterios de imputación del resultado, $2^{\mathrm{a}}$ ed, 2005, 267 siguientes; acerca de los criterios jurisprudenciales "teóricos y prácticos" acerca de la concurrencia o no de dolo.

(6) Cónfer. Laporta, El dolo y su determinación en casación, 2007. Realiza un estudio sobre el dolo, partiendo de si el dolo se prueba o se imputa, pero lo esencial es que plantea la cuestión en el contexto del Derecho penal económico y criticando las consecuencias que en este ámbito, pienso que en todos, plantea una concepción psicologicista del dolo. 
de la antijuridicidad se considera actualmente, por la doctrina mayoritaria, en el ámbito de la culpabilidad y afecta a la problemática del error de prohibición. El "dolo natural" es un concepto más restringido de dolo, que aparece por primera vez en la obra de Welzel y que no incluye la conciencia de la antijuridicidad. No obstante, recientemente hay autores que, desde perspectivas diferentes, proponen una reformulación del dolo(7), en el que se incluiría el conocimiento de la prohibición.

El "dolo natural" tiene dos elementos: conocimiento y voluntad y se concibe como "conocer y querer la realización de la situación objetiva descrita por el tipo de injusto". Este concepto de dolo natural es el que actualmente defiende la doctrina mayoritaria. De este dolo es necesario concretar dos aspectos: 1) Qué se entiende como "voluntad" y en qué medida se puede diferenciar ésta de la "voluntad mala" propia del dolus malus; y 2) Qué se entiende por "situación objetiva descrita por el tipo injusto", es decir, cuál es exactamente el objeto del dolo: qué elementos han de estar abarcados por éste. $Y$ en este punto hay que evidenciar que también son objeto del dolo natural los elementos normativos del tipo, ya sean expresos o tácitos o se trate de leyes penales en blanco. Esta cuestión afecta al llamado error de subsunción, que la doctrina mayoritaria califica como error de prohibición cuando debería considerarse error de tipo ${ }^{(8)}$. Es error de tipo porque supone desconocimiento de un elemento del tipo o al menos de su verdadero significado. Que ese elemento sea normativo en nada debería afectar a que siendo un elemento del tipo, el error sobre su concurrencia se deba calificar como error de tipo. Máxime cuando en realidad todos los elementos del tipo son normativos ya que su interpretación no se lleva a efecto a partir de una interpretación exclusivamente gramatical sino jurídica. Piénsese, como ejemplo, en el concepto penal de muerte y de vida independiente, con las diferentes posturas que existen, y que afecta a un elemento aparentemente "no normativo" como es el de persona viva, en los delitos de homicidio o aborto. Y esta normatividad de los requisitos típicos concurre en mayor medida en los delitos socioeconómicos.
El elemento volitivo del dolo, entendido como "querer" o como "voluntad" es, precisamente, el caballo de batalla del dolo eventual. En primer lugar, es necesario distinguir "querer" de "desear". Para que sea posible afirmar el "querer" es necesario que se reconozca la existencia de factores de riesgo que hacen posible la realización típica. Si el sujeto no conoce el riesgo inherente a su conducta, no es posible hablar de "voluntad de realización típica", sino únicamente de "deseo de realización típica". En un ejemplo propuesto por Herzberg, el boxeador desea la muerte de su adversario y, en un combate en el que cumple todas las reglas del boxeo, el contrincante muere por un problema físico que tenía y que desconocía el otro. Que el boxeador "desee la muerte de su contrincante" no será dolo si no conoce "la especial constitución" de su adversario y respeta las "reglas técnicas", que rigen en el boxeo; mientras que, si conociese la especial constitución, cabría hablar de homicidio doloso, pese al "cumplimiento de las "reglas técnicas"(9).

El segundo aspecto a considerar es el alcance que se dé al término "querer", o, según otros autores, a la "voluntad", en una palabra, al elemento volitivo del dolo. En la doctrina finalista, el concepto de acción final, tiene ya un componente volitivo, al caracterizarse ésta como "ejercicio de actividad final"; la acción concebida como voluntad conducida finalmente, implica que la finalidad, sea elemento de ésta y, al mismo tiempo, llene de contenido al elemento volitivo del dolo. Esto explica que la doctrina de la

(7) Cónfer. Jakobs, Dolus Malus, 2009. Parte de una de las ideas centrales de su obra, la fidelidad jurídica, para concluir que la indiferencia también debe ser calificada como dolo. Considera que la falta de interés no es conocimiento pero tampoco es error y entiende que lo que denomina "dolus indirectus" es también dolo y no imprudencia. Su planteamiento, en cierta medida, aunque con una fundamentación muy diferente, se acerca al concepto anglosajón de la recklessness o ignorancia deliberada. Analicemos uno de los ejemplos que plantea: dos sujetos hacen caer una carpa bajo la cual se encuentra un gran número de personas para evitar que siga la función, uno ha pensado que se podría provocar una situación de pánico con consecuencias mortales y el otro no. Evidentemente en esta caso la conducta es dolosa para ambos, independientemente que se alegue que uno de ellos no pensó en las consecuencias mortales. Nos encontramos frente a un supuesto que tradicionalmente se incluiría en el dolo directo de segundo grado, y la razón que la conducta de ambos sea dolosa es porque, independientemente de lo que querían, lo relevante es que no podían confiar en que no se produjeran resultados lesivos siendo "indiferente" que les fuera "indiferente" la muerte de las personas o no.

(8) Cónfer. Fakhouri, Teoría del dolo vs. teoría de la culpabilidad - Un modelo para afrontar la cuestión del error en Derecho penal, 2009. Se plantea la cuestión del error sobre elementos normativos, calificado tradicionalmente por la doctrina, como error de subsunción a considerar como error prohibición, y entiende que ello afecta al injusto y no a la culpabilidad. Siendo cierto este planteamiento la solución no está en considerar que el dolus malus también forma parte del injusto sino en la consideración de estos elementos normativos conforme a su naturaleza de elementos típicos y, en consecuencia, calificar directamente este error como error de tipo.

(9) Cónfer. Herzberg, Die Sorgfaltwidrigkeit im Aufbau der fahrlässigen und der vorsätzlichen Straftat, 1987, 537 y siguientes. 
acción final tropieza con obstáculos, creo que insalvables, en el ámbito de la imprudencia, en especial en la culpa inconsciente. Incluso sectores doctrinales, no adscritos al finalismo ortodoxo, entienden que el elemento volitivo del dolo ("querer") consiste en la resolución de ejecutar la acción típica.

El elemento volitivo del dolo, así concebido, presenta innumerables problemas, tanto materiales como formales. Desde una perspectiva material, juzgar sobre "la resolución criminal" determina la necesidad de entrar en la "intimidad psíquica" del autor lo que, con independencia de la poca fiabilidad de los resultados que se obtendrían dado el estado actual de la psicología, nos llevaría, en muchos casos, a concluir que la "voluntad" que llevó al sujeto a actuar no guardaba ninguna relación con la realización típica. Se pueden pensar, en este sentido, en un interminables número de casos: el sujeto que comete unos abusos deshonestos "con la voluntad" de perjudicar el buen nombre de su padre al que odia, el individuo que realiza un atraco "con la voluntad" de salir en los periódicos; sin entrar ya en finalidades más ocultas del subconsciente que podrían descubrirse en el examen de la psique del sujeto y que, probablemente, ni siquiera él conoce.

Junto a este primer problema se encuentra, el no menos importante, de la prueba de un proceso psíquico, que tendrá que fundamentarse, en todo caso, en los indicios que muestran los hechos externos. Ante esta dificultad, la voluntad políticocriminal, que se advierte tras la exigencia del elemento volitivo, de restringir el ámbito del dolo a los supuestos en que se constate una "voluntad criminal", se ve refutada de pleno por la práctica jurisprudencial. La jurisprudencia ante la dificultad insalvable, en muchos casos y, en particular, en los casos de dolo eventual, de probar la existencia del elemento volitivo, se guía en su decisión sobre la existencia o no de dolo por criterios totalmente ajenos a éste en la mayoría de supuestos a partir del carácter del sujeto y, en especial, de sus antecedentes delictivos $^{(10)}$. La exigencia de constatar un elemento volitivo en el dolo, entendido como resolución criminal, junto a la imposibilidad de encontrar esta "voluntad" en los supuestos de dolo eventual, conduce a un sector doctrinal a excluir el dolo eventual del ámbito del dolo, mientras que otros autores, en base al menor contenido de injusto del dolo eventual (como consecuencia del menor alcance del elemento volitivo en estos supuestos), proponen la aplicación, en estos casos, una atenuación análoga a la tradicionalmente conocida como "atenuante de preterintencionalidad"(11).
Otro sector doctrinal, en sentido opuesto, y al que me adhiero en este punto, considera el dolo eventual como auténtico dolo, en otras palabras, como el tipo básico de dolo. Desde esta perspectiva se entiende que no es necesario el elemento volitivo en el dolo, y no sólo por la dificultad de prueba, sino por razones dogmáticas. De acuerdo con una concepción del injusto, como injusto del hecho, en el que lo relevante es la creación de un riesgo típicamente relevante conocido por el autor, a sensu contrario, es irrelevante la intención del autor que le mueve a actuar. Para esta postura doctrinal la exigencia del elemento volitivo en el dolo y, en particular, de "querer el resultado", es un residuo del concepto tradicional de dolo como dolus malus. En esta línea, de eliminar vestigios del dolus malus en el dolo natural, existentes en tanto se mantenga el elemento volitivo, puede plantearse la posibilidad de comprender la "voluntad" del dolo en el sentido de "comportamiento voluntario", que no choca ya con la "voluntad" propia del dolo eventual, ya que el "comportamiento voluntario" es presupuesto general y esencial de todo delito. Aun cuando, a primera vista, parezca que con ello lo único que se hace es eliminar el elemento volitivo del dolo, no es totalmente cierto. El "comportamiento voluntario" está, necesariamente, en relación con los conocimientos que el sujeto tenga sobre la relevancia del riesgo propio de su conducta, por lo que el contenido de la voluntad es, consecuentemente, distinto cuando el sujeto actúa conociendo la relevancia típica de su conducta -dolo- que si no la conoce, al menos en su exacta virtualidad -imprudencia-. La existencia de comportamiento voluntario unido al conocimiento propio del dolo constituye el contenido de la "voluntad" propio de los hechos dolosos. El elemento "voluntario" que acompaña al comportamiento tiene un contenido distinto en los hechos dolosos y en los imprudentes, como consecuencia

(10) Cónfer. Corcoy, En el límite entre el dolo y la imprudencia, 1985, 257-274. Se pone de manifiesto como en la sentencia comentado la fundamentación del dolo de matar se basa, esencialmente, en el hecho de que el imputado se dedicaba al tráfico de drogas. Esta doctrina jurisprudencial se mantiene en la actualidad aun cuando se le esté dando una argumentación "moderna" a partir del concepto de "ignorancia deliberada". Ejemplo de esta jurisprudencia lo encontramos, entre otras muchas, en la STS de 30 de septiembre de 2009 (Ponente Marchena Gómez).

(11) Cónfer. Bustos, Manual de Derecho penal español. Parte General, 1984, 247 y siguientes. 
inmediata del distinto nivel de conocimiento existente en uno y otro caso. En términos de teoría de la norma, la contradicción con la norma de prohibición es mayor cuando el sujeto reconoce la probabilidad de lesionar un bien jurídico que cuando no sucede así, lo que justifica el mayor desvalor del injusto doloso respecto del imprudente.

Con ello, se quiere poner el acento en que, aun cuando el elemento cognoscitivo, el conocimiento de los hechos, es propio tanto del dolo como de la imprudencia consciente, el contenido del conocimiento es distinto en uno y otro caso. La importancia que tiene el conocimiento que posee el sujeto respecto del riesgo que crea su conducta se pone de relieve el examinar la culpa consciente. En ésta el sujeto tiene que contrarrestar, de algún modo, el conocimiento del riesgo que posee, para que no se le atribuya al hecho el carácter de doloso. En el homicidio, el elemento del tipo es la "idoneidad de la conducta para causar la muerte de una persona", y es "esta idoneidad en el caso concreto para causar la muerte", lo que debe conocer el sujeto para que pueda calificarse el hecho como doloso. Para que el homicidio sea imprudente, el sujeto debe desconocer la idoneidad de su conducta para causar la muerte de una persona en el caso concreto -por concurrir un error sobre la efectiva peligrosidad de su conducta o/y sobre su capacidad de evitación.

Otro aspecto del "dolo natural" que está necesitado de concreción es cuál deba ser el objeto del dolo -qué elementos debe de abarcar. Para contestar este punto es necesario determinar, en primer lugar, qué es o qué se entiende por "situación objetiva descrita por el tipo de injusto". Si esta situación objetiva es la "creación de un riesgo típicamente relevante", como tipicidad de la conducta, éste será el objeto del dolo. El primer requisito necesario, para que pueda hablarse de dolo, es que exista un riesgo normativamente relevante. Objeto del dolo, son pues, los hechos externos en cuanto peligrosos, ya que si se conoce el "dato objetivo", pero se desconoce el riesgo típicamente relevante que representa ese "dato objetivo", ese aspecto no es objeto del dolo. El dolo ha de abarcar los elementos típicos en tanto que constitutivos del injusto, tanto descriptivos como normativos y tanto esenciales como accidentales. Objeto del dolo es pues la conducta, no el resultado ni la relación de riesgo, ya que éstos no pertenecen al injusto. Cuestión diferente es que el conocimiento del riesgo típico implica el conocimiento de su idoneidad para producir un determinado resultado y que, por consiguiente, si se conoce el riesgo pero no su idoneidad no hay dolo respecto del resultado.

La doctrina, que podemos considerar mayoritaria, entiende, por el contrario, que el dolo abarca a todos los elementos pertenecientes al tipo legal, con lo que se incluye tanto el resultado como el curso causal. Esta concepción, unida a la exigencia del elemento volitivo, como "resolución de ejecutar la acción típica”, debería conducir, necesariamente, a negar el carácter de dolo, no sólo al dolo eventual, sino también al dolo directo de segundo grado, ya que, tampoco en esta clase de dolo se exige "querer" el resultado. Los efectos de esta concepción del dolo, deberían conllevar, por ejemplo, en las lesiones, a la necesidad de probar, en cada caso, si el sujeto "quería" que la víctima necesitase de quince días de asistencia facultativa o de tres meses o, en su caso, que quedara inutilizado su riñón. $\mathrm{O}$, en el ámbito de la delincuencia socioeconómica, si el autor "quería" contaminar o defraudar a la hacienda pública. En la práctica jurisprudencial la pretendida exigencia de la concurrencia de "intención" sirve a los tribunales para absolver, especialmente, en delitos de prevaricación o de falsedades documentales por notario ${ }^{(12)}$.

La problemática enunciada puede apreciarse analizando brevemente las diferentes modalidades de dolo elaboradas por la doctrina. En relación con las clases de dolo, atendiendo al contenido de conocimiento y voluntad, la doctrina es unánime en distinguir tres modalidades de dolo de las cuales únicamente en el llamado "dolo directo de primer grado, es predominante el elemento volitivo y, en concreto, la intención de producir el resultado. Por el contrario en el denominado "dolo directo de segundo grado" no se considera necesaria una voluntad dirigida al resultado sino únicamente una alta probabilidad de que el resultado se produzca. En definitiva se sigue la teoría de la probabilidad, siendo la única diferencia cuantitativa, no cualitativa. Por último en el dolo eventual se discute tanto su contenido como su posibilidad de punición como dolo. Las diversas teorías clásicas que se han elaborado sobre el dolo, del consentimiento, de la probabilidad, el sentimiento, la indiferencia, tratan de "buscar", "idear", "crear" el elemento volitivo, en relación con el resultado.

(12) Así, por ejemplo, en la STS 516/2016, de 13 de junio, en relación con un delito de prevaricación ambiental, la "intención" presuntamente requerida por el tipo "sirve" como excusa para absolver al alcalde que concedió la licencia porque "el delito de prevaricación requiere dolo directo, entendido como "intención deliberada y plena conciencia de la ilegalidad"”. 
El problema surge porque la voluntad dirigida al resultado es patrimonio exclusivo del dolo directo de primer grado, por lo que también entraría dentro de lo posible entender que la intención ( $A b s i c h t$ ) es un elemento agravatorio del injusto, que convierte al dolo directo de primer grado en un "dolo cualificado" y no un elemento esencial del concepto de dolo, mientras que, el dolo eventual, pasaría a constituir la modalidad básica de dolo, puesto que contiene todos los elementos esenciales de éste. En este sentido es relevante la consideración del resultado como condición de punibilidad, lo que no supone negarle importancia sino independizarlo del injusto típico conformado exclusivamente por el riesgo típico doloso o imprudente. En concreto, en relación con el contenido del dolo hay que resaltar que el hecho de que el resultado no sea objeto del dolo, no quiere decir que no se le tome en consideración. Siendo, el objeto del dolo el riesgo propio de la conducta y exigiendo el conocimiento de ese riesgo típicamente relevante se deduce, de forma inmediata, la afirmación de que el sujeto ha previsto el resultado. El resultado previsible está implícito en el riesgo conocido por el autor: el conocimiento propio del hecho doloso comprende la "previsibilidad individual del resultado". En la culpa consciente, junto a la previsibilidad del resultado por el agente, se han de constatar los datos objetivos por los que, en el caso concreto, es posible excluir el conocimiento de la efectiva realización.

La determinación de la existencia de dolo ha de considerarse ex ante, en el momento en que se desarrolla la conducta del sujeto, siendo irrelevante un dolo antecedente o subsiguiente. El dolo es pues conocimiento ex ante por el autor del efectivo riesgo concurrente en su conducta. La imprudencia, en particular la denominada "culpa consciente", supone conocimiento del riesgo pero error sobre su efectividad. El conocimiento requerido no debe interpretarse como un "estado mental" sino que, como veremos en el apartado siguiente, se fundamenta en datos objetivos que permiten probar que en el caso concreto, el autor, atendiendo a las circunstancias concurrentes, conocía el riesgo típico.

\section{Responsabilidad subjetiva. Especial consideración de su prueba en el proceso.}

La postura anterior se encuentra en la línea del funcionalismo que, en sus diversas vertientes, ha conllevado que el dolo, desde una perspectiva dogmática, se conciba como atribución o imputación. Imputación que en algunos autores, por ejemplo, en la obra de Pérez Barberá (Pérez 2011), conduce a un dolo absolutamente normativizado, que no es posible diferenciar de la imprudencia consciente o en la de Jakobs que afirma la existencia de dolo aun cuando el autor no tenga una representación efectiva, con un planteamiento que lo acerca a las antiguas teorías de la indiferencia (Jakobs 2004, 345 y siguientes). Otros autores, desde la perspectiva del proceso, ponen el acento en la prueba del dolo, tal y como ya proponía Ragués i Vallès, en 1999 (Ragués 1999). Propuestas muy relevantes puesto que, consciente o inconscientemente, suponen advertir que el respeto de las garantías constitucionales en el proceso, en particular el principio acusatorio, determina que no sea posible exigir para el dolo requisitos que no puedan ser probados positivamente. Paralelamente a lo anterior se niega que el dolo sea un estado mental, posicionamientos coherentes con la ubicación del dolo en el injusto, a partir del finalismo ${ }^{(13)}$. Precisamente, por el origen en el finalismo del cambio de ubicación del dolo en la teoría del delito, para el que es fundamental el concepto de acción final, el dolo siguió teniendo un componente psicológico relevante que ha estado lastrando las diversas concepciones sobre el dolo hasta épocas muy recientes. Así mismo, el concepto de dolo depende de las finalidades que se atribuyan al Derecho penal y, desde una perspectiva preventiva, es indiferente el "estado mental" del autor. Así mismo la concepción de la norma penal como norma imperativa, no valorativa, que pretende motivar al ciudadano, determina que lo relevante en la distinción entre dolo e imprudencia sea la mayor contradicción con la norma del hecho doloso (Corcoy 1989, 267 y siguientes) $)^{(14)}$.

No obstante, negar que el dolo sea un estado mental no implica que deba excluirse del dolo la exigencia de conocimiento del riesgo típico (Pérez 2011, 127) (Jakobs 2004, 347). La solución propuesta por Pérez Barberá (2011, 133 y siguientes) de diferenciar entre dolo e imprudencia a partir del grado de prever implica que la diferencia entre

(13) En este sentido, por todos, Pérez Barberá en El dolo eventual. Hacia el abandono de la idea del dolo como estado mental. Asimismo, Sánchez-Málaga Carrillo en Una teoría para la determinación del dolo. Premisas teóricas e indicadores prácticos.

(14) A partir de concebir la norma penal como norma imperativa que pretende la motivación del ciudadano, la contradicción es mayor en el hecho doloso que en el imprudente. 
dolo e imprudencia sea meramente cuantitativa, puesto que el tipo subjetivo imprudente se fundamenta, precisamente, en el deber de prever por parte del autor ${ }^{(15)}$. En la imprudencia no es necesario el conocimiento, imprudencia inconsciente, $\mathrm{y}$, como veremos, incluso la imprudencia consciente supone un déficit de conocimiento. Por lo demás, respecto de esta propuesta, habría que preguntarse si el mayor o menor deber de prever no depende del conocimiento que el sujeto tenga de las circunstancia concurrentes, en definitiva en su nivel de conocimiento del riesgo típico.

Una concepción normativa del dolo como conocimiento implica que éste no debe ser entendido como un estado mental, que deba probarse desde una perspectiva psicológica, tratando de situarse en la mente del autor, sino que el conocimiento se atribuye como un hecho que se prueba por medio de indicios (datos objetivos) $^{(16)}$. Al respecto es relevante determinar qué se necesita probar y ello implica definir el concepto de dolo como conocimiento sin necesidad de probar la voluntad que, en todo caso, está implícita en el presupuesto del delito: conducta humana voluntaria ${ }^{(17)}$. Por consiguiente es posible objetivar el dolo sin prescindir del conocimiento ${ }^{(18)}$. En definitiva se trata de objetivar este último, entendiendo el dolo como un juicio subjetivo-normativo de atribución, siendo especialmente relevante que "la valoración del contexto personal del imputado, como baremo de determinación de los indicadores de conocimiento (a efectos de una imputación dolosa) o de defectos de conocimiento (a efectos de una imputación imprudente) en el caso concreto"(19), se lleve a efecto en el ámbito del injusto no de la culpabilidad.

Paralelamente otros posicionamientos como el de Molina Fernández, ante las dificultades materiales/ontológicas (Sánchez Málaga 2018, 226) ${ }^{(20)}$ que presenta trazar una frontera clara entre dolo e imprudencia, proponen la existencia de más títulos de imputación (Molina 2005, 692-733)(21). Con un planteamiento diferente, en relación con los supuestos de ignorancia deliberada, Ragués i Vallès, propone de lege ferenda, un nuevo título de imputación para esos casos (Ragués 2013, 11-38). Siendo evidente la dificultad y la existencia de casos límites, crear más títulos de imputación únicamente multiplicaría el problema ya que supondría elaborar requisitos que permitieran diferenciarlos. La solución puede estar, no tanto en crear nuevos títulos de imputación, sino en reducir la enorme diferencia de penas que en la mayoría de legislaciones existe entre el dolo y la imprudencia. Se trataría por tanto de que el margen de discrecionalidad del juzgador fuera mayor para poder adecuar la pena en los supuestos límites -zonas grises- entre dolo e imprudencia (Molina 2005, 740) $)^{(22)}$.

En particular, sobre la exigencia de "querer" en el dolo, creo que es muy acertada la crítica de Kindhäuser, a la que nos referimos al inicio del trabajo(23), al afirmar que no tiene ningún significado exigir un elemento en el dolo que luego no puede ser apreciado. La certeza de esta afirmación se pone de manifiesto a través de un análisis de la doctrina jurisprudencial al respecto donde de nuevo se advierte la interrelación ineludible entre el Derecho penal material y el Derecho penal procesal. Ciertamente no puede afectar al Derecho penal material que en algunos casos no puedan probarse determinados

(15) En este sentido, la propuesta de Pérez Barberá es coherente, ya que considera que el dolo supone un plus respecto de la imprudencia, el autor infringe la misma norma penal, no un aliud, en el sentido que propone Jakobs $(1997,371)$.

(16) En este sentido, es relevante la actual línea jurisprudencial que concibe el dolo como un hecho, que forma parte de la vertiente fáctica (hechos probados) y que, por consiguiente, su prueba requiere las mismas garantías que los aspectos de naturaleza fáctica. Por todas, SSTS 968/2004, 29 de julio, "la constatación del dolo es una cuestión jurídica que se debe llevar a cabo a través de una serie de indicadores de carácter objetivo que se refieren a la disposición interna del autor en el momento del hecho"; 772/2004, 16 de junio: "la definición clásica de dolo trae consigo dificultades que han propiciado un concepto normativo de dolo"; 126/2012, de 18 de junio.

(17) No obstante, la jurisprudencia del TS (ver nota anterior), sigue refiriéndose a la necesidad de probar la voluntad.

(18) Cónfer. Herzberg, Das Wollen beim Vorsatzdelikt und dessen Unterscheidung vom Bewujt fahrlässigen Verhalten, 1998,575 y siguientes.

(19) Cónfer. Sánchez-Málaga Carrillo en Una teoría para la determinación del dolo. Premisas teóricas e indicadores prácticos, 2018, 257 y siguientes; apartándose en este punto de la postura de Ragués i Vallès en El dolo y su prueba en el proceso penal, 336, que sitúa la valoración en la culpabilidad.

(20) Sánchez-Málaga realiza un análisis crítico de la propuesta de Molina Fernández, poniendo de manifiesto que mantiene el problema del tratamiento del dolo en el marco de un enfoque psicológico.

(21) Molina Fernández advierte que "la introducción de números intermedios en cualquier número finito lo único que hace es desplazar a los nuevos escalones el problema que antes teníamos para decidir el punto de corte en la transición de verdadero a falso".

(22) Molina Fernández propone que el juez contara con "grados penales no sólo graduales, sino contiguos que agotaran toda la escala de punibilidad entre el mínimo de la imprudencia leve y el máximo del dolo".

(23) Supra nota 3. 
elementos pero no es viable exigir un requisito que no puede probarse en ningún caso, como no sea con la confesión del acusado, con todos los problemas que ello suscita.

Tanto la doctrina como la jurisprudencia persiguen fijar la frontera entre dolo e imprudencia, partiendo del dolo y del contenido que a éste le atribuyen. Si, por el contrario, partimos de dotar de contenido al tipo subjetivo imprudente, se puede invertir el planteamiento anterior y partir del concepto de imprudencia en lugar del de dolo para intentar proponer criterios de delimitación entre dolo e imprudencia (Corcoy 1989, 207 y siguientes)(24). Para conseguirlo, nos hemos de preguntar si, dada una misma conducta y un mismo conocimiento de su peligrosidad, podemos encontrar algún elemento que, de concurrir, implique imprudencia, en vez de buscar uno que condicione el dolo. Creo que es posible afirmar que la doctrina estaría de acuerdo en que es característico de todo hecho imprudente el no-querer el resultado lesivo y que, no obstante, éste se produce; es decir, existe un error en el conocimiento que el sujeto tiene acerca del concreto riesgo creado o no controlado teniendo el deber de hacerlo. Por lo tanto, si pese al conocimiento de la peligrosidad de la conducta, concurren elementos que explican el error del autor al creer que su conducta no es idónea para producir el resultado, concurrirá imprudencia y no dolo.

Por ello, a partir de la concurrencia de una conducta peligrosa, es importante tomar en consideración si el autor tiene algún dominio sobre el riesgo creado o no. Muchos hechos imprudentes, con culpa consciente, son tales y no dolosos, por la sobrevaloración del autor de sus posibilidades de control. En este contexto entrarían los supuestos de "autopuesta en peligro" no, únicamente porque "el riesgo que haya corrido el propio autor" pueda en ciertos casos ser "racionalmente indicativo de la culpa frente al dolo"(25), aún cuando ello pueda ser otro factor en la prueba de la ausencia de dolo, sino básicamente por el hecho de que, en estos casos, el sujeto mantiene el control del peligro. La falta de "dominabilidad" (Steuerbarkeit) del autor sobre su propia conducta puede, en estos supuestos, fundamentar el error sobre la propia capacidad de evitación. El error sobre la capacidad de evitación es el elemento que permite, de concurrir, calificar estos hechos como imprudentes, pese a que el sujeto conociera el riesgo inherente a su conducta. Este error no podrá, por el contrario, apreciarse cuando el autor no tiene ninguna clase de control sobre las posibles consecuencias de su comportamiento. Esto sucede en aquellos casos en los que el autor, una vez creado el riesgo $-y$ conociendo su efectiva virtualidad-, deja de controlarlo, por lo que no puede tener una confianza racional en la ausencia del resultado ${ }^{(26)}$. En el ámbito de la delincuencia socioeconómica a la cuestión anterior de la autopuesta en peligro y del control sobre el riesgo, se suma la relevancia del riesgo permitido en muchos de estos delitos. Ejemplos paradigmáticos serían, por ejemplo, la gestión desleal o la corrupción en los negocios, ya que en ambos delitos en muchas ocasiones es difícil deslindar lo que sería una conducta arriesgada pero que debe valorarse positivamente conforme a parámetros económicos y la conducta típica. Lo mismo puede afirmarse respecto de delitos relacionados con el medio ambiente, la seguridad en el trabajo o la seguridad en el consumo. En estos casos la "confianza racional" debe valorarse en términos económicos, es decir desde parámetros de adecuación a las reglas que rigen en esa actividad en concreto.

Con la distinción entre supuestos en los que el autor tiene capacidad de evitación de aquéllos en que no la tiene, en base al "error", como elemento esencial del tipo subjetivo imprudente, es posible trazar ya una frontera entre dolo eventual y culpa consciente. El "error" puede recaer, según la modalidad de supuesto de que se trate, en: i) la sobrevaloración del autor sobre su capacidad de poder controlar el riesgo que crea su conducta, en aquellos supuestos en que tiene el control de ésta; ii) el desconocimiento, por el autor, de la efectiva peligrosidad de su conducta, en los casos en que no mantiene el dominio sobre la conducta, siempre que este desconocimiento tenga un fundamento racional. Fundamento racional que en los delitos socioeconómicos puede basarse en base al error sobre el alcance del riesgo permitido, las reglas vigentes en el desarrollo de esa actividad. Tanto respecto al "error sobre la capacidad de evitación" como al "error sobre la efectiva virtualidad de la conducta" hay que determinar la evitabilidad

(24) Corcoy se propone la distinción entre dolo eventual e imprudencia a partir de dotar de contenido al tipo subjetivo imprudente que, tradicionalmente, ha sido concebido por la doctrina desde una perspectiva exclusivamente negativa, como ausencia de dolo.

(25) Cónfer. Zugaldía Espinar, La demarcación entre el dolo y la culpa. El problema del dolo eventual, $1986,408$.

(26) Corcoy, 1985, en el caso objeto de enjuiciamiento en la sentencia comentada no se había planteado esta cuestión, cuando ello hubiera permitido fundamentar adecuadamente la existencia de dolo.

(27) En sentido crítico, Sancinetti considera que la normativización del dolo no dice nada respecto de su contenido. 
o inevitabilidad del error. La evitabilidad o inevitabilidad del error se dilucidará, en el primer caso, a través del criterio de la "evitabilidad" (Vermeidbarkeit), para determinar si ex ante existía capacidad de evitar el resultado; y, en el segundo, por medio del criterio de la exigibilidad (Zumutbarkeit).

En todos los supuestos en que el error aparezca, para el espectador objetivo ex ante, con los conocimientos previos y actuales del autor - previsibilidad individual-, como evitable -lo que implica afirmar el deber del sujeto de conocer el riesgo típicamente relevante-, el sujeto infringe el deber subjetivo de cuidado Ýaspecto positivo del tipo subjetivo-y, presupuesta la ausencia de dolo (aspecto negativo), realiza, por tanto, el tipo subjetivo imprudente. El sujeto infringe el deber subjetivo de cuidado al "no evitar el desconocimiento", en los casos que le es exigible. El falso conocimiento y el error tienen en este nivel el mismo significado: desconocimiento de la efectiva virtualidad del riesgo creado (o no evitado, en posición de garante). Este desconocimiento puede recaer sobre la efectiva virtualidad del riesgo (todos los supuestos de culpa inconsciente y algunos de culpa consciente) o sobre la capacidad de evitación (supuestos de culpa consciente con dominio del autor sobre el riesgo) (Corcoy 1989, 269 y siguientes).

Conforme a lo anterior, este planteamiento debe encuadrarse entre las propuestas que afirman la necesaria normativización del dolo, entre las que, por otra parte, también se enmarcan las sociológicas. Ello es así porque la decisión sobre la concurrencia de un error se plantea desde una perspectiva normativa, a partir del criterio de exigibilidad, lo que posibilita a su vez, calificar como dolosos determinados supuestos de ignorancia deliberada. No obstante, es cierto que en ese contexto caben propuestas muy diversas puesto que no hay que olvidar la razón que está llevando al abandono de concepciones volitivas para sustituirlas

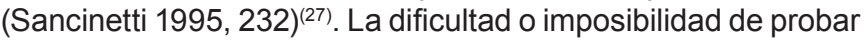
el elemento volitivo está en el origen de las teorías normativistas, aun cuando también responden a una concepción normativa del injusto, desvinculada de la culpabilidad y respetuosa con un Derecho penal del hecho. Como se ha señalado, las diversas teorías normativistas tienen en común el afirmar la naturaleza normativa del dolo, independizándolo de la psique del sujeto y obviando la necesidad de valorarla, evitando así la subjetividad que ello supone (Sánchez-Málaga 2018)(28). Conforme a estas propuestas, el conocimiento del sujeto acerca del riesgo se atribuye cuando concurren, y pueden aportarse al proceso, suficientes indicios objetivos.

No obstante, la normativización del dolo no justifica algunas teorías que se han desarrollado en ese contexto. Una de ellas sería la que propugna la exclusión del castigo en las denominadas "conductas neutrales", que serían todas aquéllas con utilidad social en las que tiene importancia el ámbito del riesgo permitido y entre las que se incluirían, muy especialmente, las conductas llevadas a efecto por profesionales, en su ámbito de actividad. La utilidad social y la profesionalidad de una conducta no justifica que se excluya el dolo, iuris et de iure, aun cuando como punto de partida se entienda que no concurre (Ragués 1999, 484 y siguientes)(29). En sentido similar es discutible el por qué en el ámbito de la delincuencia socioeconómica se considera que no hay que sancionar la complicidad, aun cuando el sujeto haya actuado dolosamente, por entender que al tratarse de una actuación profesional es riesgo permitido(30). Así mismo, requeriría que se determinara cuándo se puede calificar una conducta como "profesional". ¿Es "profesional" la conducta de un abogado, por ejemplo, de asesorar y crear un entramado societario para eludir impuestos y/o blanquear dinero? Por consiguiente, la calificación de una conducta como "neutra", por un lado, y, en sentido inverso, como "apta", no pueden ser los únicos criterios de atribución de un tipo subjetivo, imprudente en el primer caso y doloso en el segundo. Son necesarios ulteriores criterios que permitan la subsunción en uno u otro injusto en cada caso concreto.

Por otras razones, deben hacerse extensivas las críticas a las teorías sociológicas, puesto que el "inequívoco sentir social" por el que se atribuye el dolo,

(28) Sánchez-Málaga pone de manifiesto tanto lo inadecuado teóricamente como la imposibilidad práctica de defender un dolo entendido como "estado mental".

(29) Sobre las "conductas "neutrales", Ragués pone como ejemplo la conducción de automóviles como "uno de los casos más evidentes de conducta neutra con respecto a resultados como la muerte, las lesiones o los daños", afirmando que por regla general serán imprudentes pero que pueden darse excepciones.

(30) Cónfer. Robles Planas, Las conductas neutrales en el ámbito de los delitos fraudulentos. Espacios de riesgo permitido en la intervención en el delito, 2003, 17-61. Relaciona las conductas neutrales con la limitación del castigo de la complicidad, con una amplia referencia las diversas posturas adoptadas al respecto por la doctrina española y alemana. Respecto de las conductas neutrales en el ámbito socioeconómico se manifiesta muy restrictivo, por entender que la complicidad de los profesionales en estas modalidades delictivas son riesgo permitido siempre que sean propias de su actividad (página 61). 
ni es inequívoco ni se puede determinar si es "social", es decir, democrático, en cuanto expresa el sentir de la mayoría o si, por el contrario, es mediático. Y, aun cuando, verdaderamente existiera un "sentir social" es muy difícil saber cuál es y, por lo demás de saberlo va a estar determinado por los conocimientos que llegan a la sociedad sobre la verdadera naturaleza de los hechos (Ragués 1999, 341)(31). En la práctica, este sentir social va a determinarse a partir del "sentir social" del tribunal sentenciador, con lo que volvemos a la subjetividad, criticada respecto de las concepciones psicológicas. Por otra parte, si la normativización del dolo lleva a la "creación de reglas de atribución”, según ese sentir social, estas reglas sólo podrían ser indiciarias y no podrán fundamentar, sin una ulterior concreción, la existencia de dolo en el caso concreto. Por consiguiente, esas pretendidas reglas de imputación del dolo no pueden ser, en ningún caso, normas consuetudinarias que predeterminen la existencia de un injusto doloso (Laporta 2007, 181 y siguientes) ${ }^{(32)}$.

La normatividad debe plantearse en el juicio sobre el injusto típico subjetivo, en cuanto se introduzcan criterios de deber, a partir de los indicios probados acerca de los hechos y de su conocimiento por parte del sujeto, o, en su caso, del por qué del desconocimiento (ignorancia deliberada/imprudencia/impunidad). Si al sujeto, a partir de las pruebas que constan en autos, le era exigible conocer el exacto riesgo que estaba creando, o no controlando estando obligado a ello, no concurre o mejor dicho, no cabe apreciar por parte del juez ${ }^{(33)}$, el pretendido error sobre la eficacia del riesgo. En los supuestos de ignorancia deliberada lo que sucede es que el autor sabe que existe ese riesgo o que se va a producir y es por ello que se coloca en situación de no saber. Es decir, estaríamos ante supuestos de actio libera in causa en los que, teóricamente, el sujeto desconoce el riesgo en el momento en que esté se produce por qué previamente se ha colocado "dolosamente" en situación de no advertirlo(34). Siendo los supuestos de ignorancia deliberada casos límite entre el dolo y la imprudencia es imprescindible un especial cuidado para calificarlos como dolosos $^{(35)}$. En este sentido, Greco, considera que conforme al principio de legalidad, a partir de la regulación del error de tipo, si el sujeto desconoce el riesgo exacto la conducta no puede calificarse como dolosa, aun cuando el error sea vencible, ya que lo contrario infringiría el principio de in dubio pro reo (Greco 2013, 67-78). No obstante, aplicando la teoría de la actio libera in causa (Joshi 1992, 97 y siguientes)( ${ }^{(36)}$, en determinados casos, puede afirmarse que el sujeto actúa dolosamente cuando a pesar de la existencia de indicios racionales del riesgo que está creando, no se informa, pudiendo y debiendo hacerlo (Feijoo $2015,17-18)^{(37)}$. La referencia a la actio libera in causa es complementaria a la propuesta de Ragués i Vallès, de asimilar determinados casos de ignorancia deliberada al fraude de ley, exigiendo dos requisitos: "1. Que el sujeto haya obrado en la sospecha de estar llevando a cabo una acción u omisión potencialmente lesiva en el futuro para algún interés indeterminado; 2. Que haya permanecido en la ignorancia con el propósito de "construirse" una excusa que le exonere en el supuesto de acabar produciéndose tal lesión. El primer elemento incorpora el factor de indiferencia cualificada que, como se ha dicho, exige el tratamiento punitivo agravado del dolo respecto de la culpa; y el segundo toma en cuenta la necesidad -acentuada en los casos de dolo- de provocar con la pena el fracaso del sujeto infractor" (Ragués 2013, 156).

(31) Ragués entiende que está legitimado el sentido social como criterio de determinación del dolo y entiende que con ello se reduce el riesgo "de ser condenado como autor de un delito doloso sin haber contado (desde un punto de vista psicológico) con los conocimientos requeridos por el dolo.

(32) En este sentido, Laporta, en relación con la fundamentación de la Cámara Nacional de Casación del dolo en un delito de libramiento de cheque sin provisión de fondos, en base al cumplimiento de la formalidad de que el tenedor del cheque haya enviado la interpelación correspondiente al domicilio constituido por el librador. Como pone de manifiesto el autor, este criterio no puede ser estático y, por consiguiente, esa regla, en cuanto responda al sentido social "es un criterio de atribución normativa del tipo subjetivo, pero no el único, por lo que debe entrar en juego con los restantes criterios y principios".

(33) Cónfer. Freund, Normative Probleme der "Tatsachenfeststellung, 1987, 50 y siguientes. Plantea que siempre existe un riesgo de error por parte del juez, y por consiguiente dudas, cuando se condena un hecho como doloso pero que pese a ello es posible y legítimo condenar por delitos dolosos, sin infringir el principio in dubio pro reo.

(34) Supra nota 7, acerca de la teoría de Jakobs sobre el dolus malus y, en concreto, al ejemplo de la carpa propuesto por éste; vid. también Ragués en El dolo y su prueba en el proceso penal, 1999, 168 y siguientes. Plantea el problema que suscitan las "ausencias irracionales de representación del riesgo", como uno de los problemas que plantean las teorías cognitivas.

(35) Cónfer. Sánchez-Málaga Carrillo, Una teoría para la determinación del dolo. Premisas teóricas e indicadores prácticos, 385 y siguientes. Plantea el problema de la ignorancia deliberada a partir del primer caso en que se suscitó en EEUU, caso Regina $v$ Sleep (1861) Leigh and Cave 44, 169 ER 1296.

(36) Joshi diferencia entre dolo antecedens, dolo subsequens, dolus generalis y versare in re illicita.

(37) Feijoo considera que hay dolo cuando el sujeto "busca fraudulentamente excluir responsabilidades". 
En definitiva, serán dolosos los "supuestos de actio libera in causa en los que el sujeto desconoce el riesgo en el momento en que éste se produce porque previamente se ha colocado "dolosamente" en situación de no advertirlo (...)" (Corcoy 2016, 93). En consecuencia, "es necesario probar que (el imputado) conocía la concurrencia de un riesgo idóneo para producir el resultado, aun cuando se negara a saber sus términos concretos" (Corcoy 2016, 94). En todo caso, sea o no de ignorancia deliberada, concurre dolo cuando éste se fundamenta y prueba a partir de datos objetivos relativos a la naturaleza y eficacia del riesgo creado, no cuando se basa en la situación psíquica del autor en el momento del hecho porque ello supone volver a valorar la psique el sujeto. Cuestión diferente es que si se prueba que el autor ha exteriorizado su conocimiento y/o su voluntad de que se produzca el resultado, esta exteriorización es un dato relevante que puede fundamentar el dolo.

\section{Peculiaridades de la responsabilidad subjetiva en la delincuencia socioeconómica. La atribución de autoría como premisa}

Los problemas específicos de la responsabilidad subjetiva en la delincuencia socioeconómica requieren poner de manifiesto ciertas peculiaridades e implican que es imprescindible ponerlo en relación con la atribución de autoría. Con carácter general, tradicionalmente, en la dogmática penal la cuestión de la autoría se ha tratado como algo diferente/posterior al injusto, de alguna forma desvinculada de éste ${ }^{(38)}$. No obstante, la atribución de autoría debe ubicarse en el injusto típico, puesto que no es posible determinar de forma adecuada cuál es el hecho típico sin determinar a quién/quiénes puede atribuirse. Ello se evidencia en el aspecto subjetivo ya que es imposible saber si concurre dolo, imprudencia o si el hecho es atípico, sin conocer a qué persona/s nos estamos refiriendo. Sea cual sea la concepción del dolo que se defienda se evidencia la imposibilidad de determinar el aspecto subjetivo sin una referencia al autor. Es evidente que la relevancia es mayor desde posiciones que defienden un dolo psicologicista pero también es imprescindible desde posturas que conciban el dolo como conocimiento. En este segundo caso, se deberá probar lo que el sujeto conocía del hecho típico o si tenía deberlo de conocerlo o si, por el contrario, ni podía ni debía conocer su concurrencia.
En el ámbito de la delincuencia socioeconómica la cuestión es si cabe más relevante ya que, cuando los delitos se han cometido en el interno de la empresa (Schünemann 1988, 529 y siguientes) ${ }^{(39)}$, es decir, "delitos que pueden entenderse como expresión de la empresa como fuente de peligro en sí misma" (Robles 2013, 322). En consecuencia, lo relevante no será quién materialmente ha realizado la conducta típica sino quién tenía competencia sobre ese riesgo típico que le pertenece como suyo y del que se beneficia y, sólo una vez se ha determinado la/s persona/s a la/s que se puede atribuir el hecho en concepto de autor, analizar si conocía/n o debía/n conocer la concurrencia de ese riesgo que estaba/n obligado/s a controlar. En particular, en el ámbito de la delincuencia socio-económica, en la mayoría de supuestos, la autoría se atribuye por comisión por omisión, autoría mediata o autor detrás del autor, debiendo tomarse en consideración la relevancia de la delegación. Todo ello implica que el paso previo a analizar el aspecto subjetivo sea determinar a quién puede atribuirse la conducta típica, es decir, concretar quién/es tenían competencia sobre el riesgo típico o, en otros términos, quién/es tenía/n capacidad de decisión.

Aun cuando, atendiendo al objetivo de este trabajo, no puede profundizarse en la cuestión de la autoría, es necesario hacer referencia a las llamadas "conductas neutrales" y los límites de la atribución de responsabilidad a los partícipes, incluso concurriendo en ellos dolo, en base a criterios de inexigibilidad. A la primera cuestión se hizo referencia supra ${ }^{(40)}$, ya que tienen una especial relevancia, como se ha puesto de manifiesto, en la delincuencia socio-económica en orden a excluir la responsabilidad de profesionales que "colaboran" en el delito creando las estructuras defraudatorias. Sintetizando se excluye la responsabilidad de estos

(38) Ciertamente en la actualidad diversos autores han puesto de manifiesto, desde diferentes perspectivas, la íntima relación entre el injusto y la autoría. Por citar tres perspectivas diferente como Mir Puig en "Significado y alcance de la imputación objetiva en Derecho penal” (Congreso Internacional Facultad de Derecho de la UNED), 2001, página 405 y siguientes; Gómez Martín, Pertenencia del hecho, instrumento doloso no cualificado y delitos de propia mano, 2006, 11-43; Robles Planas, Los dos niveles del sistema de intervención en el delito (el ejemplo de la intervención por omisión), 2012, páginas 1-26.

(39) Schünemann, los definió, ya en los años 80, como "betriebsbezogene Tat" ("hechos vinculados a la empresa").

(40) En particular, ver notas 36 y 37. 
supuestos de participación a partir de definir esas conductas como lícitas. Licitud que se fundamenta en el hecho de que se trata de conductas "profesionales". Sin entrar en muchas más disquisiciones, no olvidemos que la mayoría de delitos contra la Administración pública y de justicia, son conductas "profesionales" de los funcionarios o autoridades, pero ilícitas. Por consiguiente, una conducta profesional no será lícita ni, por consiguiente, "neutral", si supone un abuso de su profesión. Así, por ejemplo, si entendemos que la función de un asesor fiscal es conseguir que su cliente pague lo menos posible, ese "menos" debe de moverse dentro de la legalidad. Su función, en ningún caso, es, por ejemplo, organizar una estructura societaria para poder defraudar. Afirmar que esa conducta es conforme con su "rol" profesional no parece de recibo. En cuanto son conductas que favorecen al autor del delito deben de calificarse como de participación. Los defensores de la irrelevancia penal de las conductas neutrales lo justifican, así mismo, en que esa cooperación solo lo es "términos causales", afirmando que conforme a la teoría de la imputación objetiva esas conductas son riesgo permitido. De nuevo se suscita aquí una petitio principii, ya que se parte de que son riesgo permitido para concluir en su irrelevancia penal. Es cierto que los profesionales no son garantes de riesgos ajenos (Robles 2003, 30 y siguientes), pero ello no excluye la relevancia penal de su conducta cuando contribuye activamente a la realización típica. Tampoco se trata de "castigar" a quien tiene conocimientos especiales ${ }^{(41)}$, sino a quien contribuye conscientemente al hecho delictivo de otro.

En relación con la cuestión de la inexigibilidad el problema estriba en delimitar hasta que nivel de empleados puede atribuirse responsabilidad penal, atendiendo a que las estructuras empresariales parten de la división del trabajo. Partiendo de que la atribución de autoría requiere competencia sobre el riesgo típico que le pertenece como suyo y del que se beneficia es necesario determinar el por qué no se atribuye responsabilidad a determinados empleados que, en muchas ocasiones, son quienes realizan la materialmente la conducta típica y conocen su significado delictivo. No siendo éste el lugar para profundizar en el tema, dado que excedería con mucho su alcance, puede avanzarse que únicamente cabe excluir la responsabilidad penal en base a criterios de inexigibilidad, unido al principio de fragmentariedad aplicado, en este caso, al castigo de los partícipes (Luzón 2016, 500)(42), entendida la participación como una extensión de la punibilidad respecto del autor. Inexigibilidad y fragmentariedad pueden justificar no sancionar determinadas conductas de participación en delitos de empresa pero no establecen criterios sobre cuándo al autor no le es exigible otra conducta ni cuándo, en base al principio de fragmentariedad, esa conducta no supone una contribución relevante jurídico-penalmente. En ese punto puede servir la idea de fungibilidad unida a la de beneficio/perjuicio.

En general, y muy especialmente en el ámbito de la delincuencia de empresa, por sus específicas características, hay que partir de que para la existencia de dolo es indiferente el móvil por el que se ha llevado a efecto determinada conducta. Al respecto no hay que olvidar que en la delincuencia de empresa, en el $99 \%$ de los casos, concurrirá una finalidad económica, incluso cuando estemos frente a delitos cuya naturaleza no es directamente patrimonial, como pueden ser los delitos contra el medio ambiente, seguridad en el trabajo, salud de los consumidores. Cuestión diferente es que en ocasiones la denominada "finalidad", considerada como elemento subjetivo, realmente forma parte del tipo objetivo, en cuanto está implícita en el significado del verbo típico(43).

Partiendo de que el dolo eventual es conocimiento exacto del riesgo creado o no controlado, hay que determinar qué nivel de conocimiento es necesario. Aspecto común a todos los delitos pero que por las características de la delincuencia socioeconómica adquiere una especial relevancia. El nivel requerido será el conocimiento en la esfera del profano lo que implica que no es necesario, por ejemplo en el delito fiscal, conocer la legislación tributaria, siendo suficiente que se tenga conocimiento de que no se cumple de forma relevante la referida normativa y que con ello se está defraudando a la Hacienda Pública. Y ello con independencia de que, en este delito como en general en todos los delitos de empresa, el resultado perseguido no es defraudar sino aumentar los beneficios, en definitiva, ánimo de lucro. En la misma dirección, en esta modalidad de delincuencia, atendiendo a que los autores pueden contar con asesores y profesionales, la jurisprudencia no admite

(41) Cónfer. Robles Planas, "Las conductas neutrales en el ámbito de los delitos fraudulentos (...)",35 y siguientes.

(42) Cónfer. Luzón Peña fundamenta la exclusión del castigo de los partícipes en el hecho imprudente en el principio de fragmentariedad.

(43) STS 1080/2010, 20 de octubre, absuelve del delito de blanqueo, entre otras razones relacionadas con el non is in idem, en base a que no concurría la finalidad requerida por el tipo de "ocultación" del origen ilícito del bien, puesto que entregó el dinero, procedente del tráfico de drogas, como consecuencia del chantaje del que estaba siendo objeto. 
alegar desconocimiento de la normativa aplicable ${ }^{(44)}$. Así, por ejemplo, en los delitos urbanísticos no cabe apreciar error de tipo, cuando el desconocimiento del riesgo haya sido buscado(45). En idéntico sentido, la jurisprudencia niega virtualidad a un pretendido error de prohibición ${ }^{(46)}$. En este sentido, el conocimiento que fundamenta el dolo en el delito de blanqueo no requiere conocer de forma pormenorizada el origen del objeto o del dinero, no siendo necesario que se conozca con exactitud, sino únicamente saber con certeza la procedencia ilícita de lo recibido, descartándose los casos de mera sospecha y siendo irrelevante que se conozca el nomen iuris o detalles del delito previo(47). Por razones diversas, lo mismo cabe afirmar en los delitos de estafa o apropiación indebida en los que, la propia naturaleza fraudulenta de la conducta típica conlleva la existencia de dolo y el ánimo de lucro, siendo indiferente que lo defraudado se lo quede el acusado o lo ceda a un tercero(48).

En la práctica jurisprudencial, el concepto de dolo, entendido como conocimiento exacto del riesgo típico, excluye la relevancia del "ánimo" del sujeto -móvil-. Irrelevancia que no queda desvirtuada ni tan siquiera en aquellos delitos, como por ejemplo los societarios en los que se requiere, expresamente: "ánimo de lucro propio o ajeno en perjuicio de los demás socios". Ello pone de manifiesto, al igual que sucede con el concepto de dolo, que en la jurisprudencia se defienden a nivel teórico conceptos que en la resolución concreta del caso no se siguen, ya que el "ánimo de perjuicio de tercero" se deduce directamente de la conducta dirigida a alcanzar un beneficio ilícito y ello, a su vez, se desprende de la propia naturaleza de la conducta. Se trata, por tanto, de lo que podemos denominar "declaraciones de principios" que carecen de relevancia práctica, puesto que son los datos objetivos concurrentes los que fundamentan la "prueba" del "ánimo(49). En definitiva, en relación con el ánimo se reproduce la misma situación que en el dolo: se objetiviza. Deja de ser un estado mental para probarse y deducirse del significado de la conducta típica(50).

No obstante, es cierto que, en ocasiones, la jurisprudencia sigue una forma de derecho penal de autor absolviendo a partir de la pretendida "ausencia de ánimo", lo que concuerda con lo que puede denominarse "principio de oportunidad restrictivo" o por el contrario "presume el ánimo", principio de oportunidad extensivo, según la personalidad del autor ${ }^{(51)}$. Principios de los que se ha servido en la prueba del dolo, excluyéndolo en algunos supuestos respecto de "profesionales"(52) y generalmente hasta hace muy pocos años de las "mujeres"(53). En la última década, en algunas sentencias, va modificándose la valoración de la conducta y se afirma la existencia de dolo, a partir de la

(44) Para la jurisprudencia, en la no apreciación del error reviste una especial relevancia la profesionalidad del sujeto. Así, por ejemplo, la STS 25 de abril de 2007, afirma que el director de una sucursal bancaria no puede ampararse en el desconocimiento de la normativa aplicable a la prevención del blanqueo aunque hubiera sido trasladado de Suiza a Burgos.

(45) En este sentido, STS de 25 de noviembre de 2009, en un supuesto en el que el promotor no había solicitado la licencia de obras.

(46) Cónfer. SSAP Almería 3a, 29 de abril de 2010; Sevilla 3a 26 de marzo de 2010, se pretendía fundamentar el error de prohibición en que la obra iba a ser legalizada por estar rodeada de otras también ilegales.

(47) STS 21 de enero de 2009.

(48) Cónfer. STS 10 de enero de 2010.

(49) Ello se evidencia en su interpretación de los delitos societarios en los que a nivel teórico sostiene que el "ánimo de lucro" es el criterio que permite la delimitación entre el injusto penal y el extrapenal. Cónfer. STS 796/2006, de 14 de julio o STS 17 de abril de 2004.

(50) La más que relativa importancia que se otorga a los elementos subjetivos del injusto, incluso cuando están expresamente previstos en el tipo, resulta patente, por ejemplo, en la jurisprudencia relativa a los delitos de receptación y blanqueo, en los que el tipo requiere expresamente ánimo de lucro y pese a ello para el dolo se exige exclusivamente probar el conocimiento que el autor tenía respecto del origen delictivo de los efectos sobre los que se realiza la conducta típica. En este sentido, STS 338/2007, 25 de abril, califica como elemento subjetivo el conocimiento del origen ilícito del dinero, cuando ello no supone nada diferente al dolo. En estos delitos se admite incluso el dolo eventual pese a que, a nivel de declaración de principios, afirme que los delitos que requieren un elemento subjetivo del injusto no pueden cometerse por dolo eventual (STS 1016/2010, 24 de noviembre).

(51) Cónfer. Corcoy, El delito imprudent. Criterios de imputación del resultado, 207 y siguientes.

(52) STS 801/2010, 23 de septiembre, condena por blanqueo imprudente a un asesor fiscal y contable que, según los hechos probados, realizó todas las actividades tendentes a la ocultación del dinero, siendo "perfectamente conocedor de las actividades" de las que procedía; STS 16/2009, 27 de enero, condena por delito de blanqueo por imprudencia a un abogado, al que se condena como cooperador en el tráfico de drogas y que, conforme a los hechos probados, es quien realiza todas la conductas tendentes a la ocultación del origen del dinero.

(53) STS 688/2009, 18 de junio, absuelve a la compañera sentimental del principal acusado por tráfico de drogas y blanqueo; STS 130/2007, 19 de febrero, absuelve a la compañera sentimental, condenada por la Audiencia Provincial como coautora del delito de blanqueo de capitales, curiosamente con la atenuante de parentesco, siendo ella titular de las cuentas bancarias en Andorra, donde se ingresaba el dinero procedente del tráfico y siendo administradora de una sociedad en la que se invertía en inmuebles. 
Ilamada "ignorancia deliberada", tanto de profesionales como de mujeres ${ }^{(54)}$. En definitiva, tanto el dolo como el ánimo de lucro o de perjuicio o la finalidad de perjudicar a los socios o a los deudores, se prueban a partir de los hechos constatados y, en concreto, del significado de la conducta que lleva a efecto el autor. Concurre dolo a partir del conocimiento exacto, por parte del autor, del riesgo que para el bien jurídico-penal protegido implica su conducta. Conocimiento exacto que, como se ha indicado, no implica que necesariamente conozca todos los aspectos de la actividad ilícita ni que los comprenda puesto que es suficiente el llamado conocimiento en la esfera del profano(55).

Tal y como se ha señalado en el apartado II, en los últimos años la jurisprudencia califica como dolosos los supuestos de ignorancia deliberada, concebida como: conocimiento eventual del injusto "paralelo al dolo eventual"(56). No obstante, otro sector de la jurisprudencia es crítica a la apreciación de dolo por ignorancia deliberada, por entender que es una trasposición del "willful blindness", contraria al principio de culpabilidad, ya que puede ser utilizada para eludir la prueba del conocimiento que requiere el artículo 14.1 del Código Penal o para invertir la carga de la prueba ${ }^{(57)}$. El hecho de que, particularmente en la delincuencia socioeconómica, de urbanismo o medioambiental, la conducta típica se lleve a efecto materialmente por asesores o técnicos, puede dificultar alegar la concurrencia de un error ${ }^{(58)}$. Error sobre el riesgo que supone esa actividad lo que llevaría la ausencia de dolo y, en el supuesto que no esté prevista la comisión imprudente o que el error se califique como invencible, implicaría su irrelevancia jurídico-penal. La solución no es unívoca y aun cuando no puede afirmarse sin más que no cabe error, en determinados casos estaríamos ante lo que tradicionalmente se ha denominado error burdo que equivale a inexistencia de error relevante. En consecuencia, y en este punto serían válidas las posturas que afirman el dolo en los casos de ignorancia deliberada, en ocasiones, atendiendo a las circunstancias concurrentes, es irrazonable que el sujeto afirme desconocer lo que sucedía(59). Y ello en base a que no se requiere un conocimiento pormenorizado de los hechos concretos que se realicen, siendo suficiente el conocimiento de que se está creando un riesgo típico, en cuanto idóneo para lesionar el bien jurídico penal protegido. No puede negarse que ello supone, en cierta medida, un dolo "general", lo que debería tomarse en consideración en orden a la calificación concreta de los hechos. Es decir, hay que delimitar el ámbito de riesgo que se conocía y no puede condenarse por todos los hechos objetivamente realizados sino únicamente por los tipos básicos, en aplicación del principio in dubio pro reo ${ }^{(60)}$.

\section{Conclusiones}

Atendiendo a la comprensión de la norma penal como norma de determinación, a la finalidad preventiva que se atribuye al Derecho penal, así como a las garantías procesales, en particular, el derecho de defensa, es imprescindible una objetivización del dolo. Tanto el dolo como la imprudencia debe de probarse a través de datos objetivos -hechos-, ello unido al significado externo de la conducta. En esta dirección el estado mental del sujeto es irrelevante, al menos en el nivel del injusto, aunque debería ser tomado en consideración en el nivel de la responsabilidad personal -culpabilidad-, particularmente en la imputabilidad. Este planteamiento es coherente con un Derecho penal del hecho respetuoso con el derecho de defensa y no supone castigar más, como

(54) STS 202/2007, 20 de marzo, condena por blanqueo doloso al abogado que ha diseñado y llevado a efecto toda la estrategia de ocultación, aun cuando la Sala muestra algunas reticencias, considerando que debía ser considerado cooperador necesario, pero que ello no supondría una rebaja de la pena y que el tipo amplía el concepto de autor impidiendo la calificación como cooperador; STS 145/2008, 8 de abril, condena a la mujer e hijo, en base a un elevado nivel de vida no justificado, considera razonable la convicción de los juzgadores acerca del conocimiento de ambos acerca de la irregular procedencia de los bienes.

(55) Así, por ejemplo, STS 21 de enero de 2005.

(56) Vid., entre otras, STS 1238/2009, 11de diciembre; STS 338/2007, 25 de abril.

(57) Cónfer. STS 6564/2013, considera que la ignorancia deliberada es incompatible con el principio de culpabilidad. En el mismo sentido, 8316/2012. En la STS 246/2009, 2 de abril, la incompatibilidad es sólo "aparente" porque tras la crítica aprecia la existencia de dolo.

(58) La jurisprudencia mayoritaria "presume" el conocimiento respecto de determinados profesionales "obligados" a conocer por específicas reglamentaciones de su sector. En este sentido, SSTS 2860/2015, "quien sin saber aquello que puede y debe saber está asumiendo y aceptando"; 4281/2014; 6389/2013; 1372/2009, 28 de diciembre, sobre blanqueo; 741/2007, 27 de junio, respecto de operadores financieros en el blanqueo de capitales.

(59) Cónfer. STS 338/2007, 25 de abril, afirma que, concurriendo determinadas circunstancias, colaborar no queriendo saber posibilita la atribución de responsabilidad.

(60) STS 1170/2010, 16 de diciembre, se condena por blanqueo de capitales a la esposa del principal imputado, en base a concurrir indicios de que conocía el origen ilícito de los bienes que poseía, administraba o disfrutaba, sin establecer ninguna delimitación acerca del alcance de su conocimiento, lo que tiene consecuencias en relación con los tipos agravados del blanqueo. 
pudiera interpretarse y como han afirmado sectores de la doctrina y la jurisprudencia, sino castigar en atención a los hechos probados. El injusto determina la pena máxima que puede imponerse, que podrá ser excluida, atenuada o sustituida en atención a la responsabilidad personal, nunca aumentada.

Los aspectos subjetivos, dolo, incluida la ignorancia deliberada, elementos subjetivos del injusto e imprudencia, deberán deducirse lógica y motivadamente de los datos objetivos que hayan sido probados en el proceso. La concurrencia de determinadas características psíquicas en el sujeto que afecten a su normalidad motivacional deberán considerarse en el ámbito de la culpabilidad o responsabilidad personal y determinar la pena o/y medida de seguridad en concreto aplicable. Esta estructura metodológica, no puede obviarse, suscita problemas en algunos supuestos en los que esos déficits cognitivos pueden determinar el desconocimiento del riesgo exacto creado y excluir la existencia de dolo, lo que, a su vez, plantea la cuestión de la relación entre injusto y culpabilidad, problema que desborda con mucho los términos de este trabajo.

Este planteamiento no solo es predicable respecto de la delincuencia socioeconómica, aun cuando es el ámbito en que adquiere mayor relevancia. En este sentido son relevantes las características de los autores de estas formas de delincuencia, así como la naturaleza de estos delitos. Por una parte, en relación con la autoría, se advierte que es imprescindible acudir a conceptos de autoría relacionados con el dominio/ competencia sobre el riesgo, la capacidad de decisión y la titularidad del beneficio. Así mismo, se suscita la cuestión de hasta qué nivel debería atribuirse responsabilidad penal, incluso respecto de aquella persona que realiza materialmente la conducta típica dolosamente.

La profesionalidad de los autores en la delincuencia socioeconómica, o la posibilidad de contar con asesores, unido a los deberes de garante inherentes a su situación en el control del riesgo en su propio ámbito de dominio, conllevan que sea un ámbito en el que la ignorancia deliberada adquiera una especial relevancia. En consecuencia, se limita la relevancia del error, tanto de tipo como de prohibición, en base a que tienen tanto un deber legal de conocer como facilidad para acceder a la información, aun cuando ese conocimiento lo sea en la esfera del profano.

\section{Referencias Bibliográficas}

Bustos, Juan. 1989. Manual de Derecho penal español. Parte General. Barcelona: Editorial Ariel.

Corcoy, Mirentxu. 1985. En el límite entre el dolo y la imprudencia. Anuario de Derecho Penal y Ciencias Penales.

Corcoy, Mirentxu. 1989. El delito imprudente. Criterios de imputación del resultado. $2^{\mathrm{a}}$ ed. Buenos Aires: B de F.
Corcoy, Mirentxu. 2016. En Mirentxu Corcoy Bidasolo y Victor Gómez Martín (Dirs.), Manual de Derecho Penal, Económico y de Empresa. Parte General y Parte Especial. Tom. 2.

Fakhouri, Yamila. 2009. Teoría del dolo vs. teoría de la culpabilidad - Un modelo para afrontar la cuestión del error en Derecho penal. InDret: Revista para el análisis del Derecho 4.

Feijoo, Bernardo. 2010. Funcionalismo y teoría del bien jurídico. En Constitución y principios del Derecho penal: algunas bases constitucionales, coords. Santiago Mir Puig, Joan Queralt Jiménez y Silvia. Fernández Bautista. España: Tirant lo Blanch.

Feijoo, Bernardo. 2015. La teoría de la ignorancia deliberada en Derecho penal: una peligrosa doctrina jurisprudencial. InDret: Revista para el análisis del Derecho 3.

Freund, Georg. 1987. Normative Probleme der “Tatsachenfeststellung". Heildelberg.

Gómez Martín. 2006. Pertenencia del hecho, instrumento doloso no cualificado y delitos de propia mano. RDPC 17, $2^{a}$ época.

Greco, Luis. 2013. Comentario al artículo de Ramon Ragués. En Bouvier (dir.), Discusiones No XIII. Editorial de la Universidad Nacional del Sur.

Herzberg, Rolf. 1987. Die Sorgfaltwidrigkeit im Aufbau der fahrlässigen und der vorsätzlichen Straftat. Juristen Zeitung 11 (junio).

Herzberg, Wolf. 1988. Das Wollen beim Vorsatzdelikt und dessen Unterscheidung vom Bewult fahrlässigen Verhalten. JuristenZeitung 12 (junio).

Hruschka, Joachim. 2005. Sobre la difícil prueba del dolo. En Imputación y Derecho Penal. Estudios sobre la Teoría de la Imputación (traducción de Sánchez Ostiz). Pamplona: Thomson Aranzadi.

Jakobs, Günther. 1997. El principio de culpabilidad. Estudios de Derecho penal (traducción de Peñaranda, Suárez y Cancio). España: Civitas.

2004. Indiferencia como dolo indirecto (traducción de Pérez del Valle). En Dogmática y ley penal. Libro homenaje a 
Enrique Bacigalupo, coords. Jacobo López Barja de Quiroga y José Miguel Zugaldía Espinar.

2009. Dolus Malus. InDret: Revista para el análisis del Derecho 4. Trad, Yamila Fakhouri Gómez.

Joshi, Ujala. 1992. La doctrina de la "Actio Libera in Causa" en Derecho penal (Ausencia de acción o inimputabilidad provocadas por el sujeto). Editorial JM Bosch.

Kindhäuser, Urs. 1984. Der Vorsatz als Zurechnungskriterium. En Zeitschrift für die gesamte Strafrechtswissenschaft.

Laporta, Mario. 2007. El dolo y su determinación en casación. Buenos Aires: LexisNexis

Luzón, Diego-Manuel. 2016. Lecciones de Derecho penal. Parte general. $3^{\mathrm{a}} \mathrm{ed}$. El Tirant lo Blanch.

Mir Puig, Santiago. 2001. Significado y alcance de la imputación objetiva en Derecho penal. Modernas tendencias en la Ciencia del Derecho penal en la Criminología - Congreso Internacional Facultad de Derecho de la UNED. Madrid.

2015. Derecho Penal. Parte General. $10^{a}$ ed. España: Reppertor.

Molina, Fernando. 2005. La cuadratura del dolo: problemas irresolubles, sorites y Derecho penal. En Homenaje al profesor Dr. Gonzalo Rodríguez Mourullo. España: Civitas.

Pérez, Gabriel. 2011. El dolo eventual. Hacia el abandono de la idea de dolo como estado mental. Buenos Aires: Hammurabi.
Ragués, Ramón. 1999. El dolo y su prueba en el proceso penal. Barcelona: JM Bosch Editor.

2013. Mejor no saber. Sobre la doctrina de la ignorancia deliberada en Derecho penal. En Bouvier (dir.) Discusiones No. XIII. Editorial de la Universidad Nacional del Sur.

2013. A modo de contrarréplica: la ignorancia deliberada y su difícil encaje en la teoría dominante de la imputación subjetiva. En Bouvier (dir.), Discusiones XIII. Editorial de la Universidad Nacional del Sur.

Robles, Ricardo. 2003. La participación en el delito: fundamentos y límites. Barcelona: Marcial Pons.

2003. Las conductas neutrales en el ámbito de los delitos fraudulentos. Espacios de riesgo permitido en la intervención en el delito. En ¿Libertad económica o fraudes punibles?: riesgos penalmente relevantes e irrelevantes en la actividad económica empresarial, coord. Jesús Silva Sánchez. España: Marcial Pons.

2012. Los dos niveles del sistema de intervención en el delito (el ejemplo de la intervención por omisión. InDret: Revista para el análisis del Derecho 2.

2013. El responsable de cumplimiento - compliance officer - ante el Derecho penal. En Criminalidad de empresa y compliance. Prevención y reacciones corporativas. Jesús Silva Sánchez y Raquel Montaner Fernández, Editorial Atelier.

Sancinetti, Marcelo. 1995. Fundamentación subjetiva del ilícito y desistimiento de la tentativa. Bogotá: Editorial Temis.

Sánchez-Málaga, Armando. 2018. Una teoría para la determinación del dolo. Premisas teóricas e indicadores prácticos. Buenos Aires: Editorial B de F.

Schünemann, Bernd. 1988. Cuestiones básicas de la dogmática jurídico-penal y de política criminal acerca de la criminalidad de empresa (traducción de D. Brükner y Lascuraín Sánchez). Anuario de Derecho Penal y Ciencias Penales.

Zugaldía, José. 1986. La demarcación entre el dolo y la culpa. El problema del dolo eventual. Anuario de Derecho Penal y Ciencias Penales. 